\title{
Interval-valued Pythagorean fuzzy AHP method-based supply chain performance evaluation by a new extension of SCOR model: SCOR 4.0
}

\author{
Ertugrul Ayyildiz $^{1} \mathbb{D} \cdot$ Alev Taskin Gumus $^{1}$
}

Received: 1 June 2020 / Accepted: 16 October 2020 / Published online: 4 November 2020

(c) The Author(s) 2020

\begin{abstract}
Supply chain operations reference (SCOR) is a combined benchmarking, business process reengineering, and best practices, and it also references a model that is intended to be an industry standard. SCOR model is one of the best models to describe supply chain activities in operations management for research and practice alike. There are radical changes in the structure of supply chains as well as developing technology in today's information age. The purpose of this paper is to extend the SCOR model with new metrics related to Industry 4.0 and digitalization to understand and evaluate the performance of supply chains. New metrics added to the SCOR model and a novel SCOR 4.0 model is proposed. The novel performance evaluation model is structured as a three-level hierarchical structure to evaluate the supply chain. This problem is handled as a multi-criteria decision-making problem. This study uses the hybrid Best worst method and Pythagorean fuzzy AHP method to determine the weights of metrics. SCOR model is adapted to performance evaluation of the supply chain in the globalizing world. The most important metrics on the supply chain performances are determined and classified. Level 1 metrics are evaluated by Best worst method and their inner levels are evaluated by the Pythagorean fuzzy AHP method and the importance weights of each level 2 and level 3 metrics are obtained. A real application for the oil supply chain is presented to show the applicability of the proposed model. It is aimed to show the SCOR 4.0 model can be used by both public and private sectors to improve their supply chain strategies in globalizing world.
\end{abstract}

Keywords SCOR; Pythagorean fuzzy AHP · Best worst $\cdot$ Supply chain performance evaluation

\section{Introduction}

In general, the supply chain links the sources of supply (suppliers) to the owners of demand (end customers). The ultimate goal of any supply chain is to deliver the right supplies in the right quantities to the right locations at the right time. Supply chains comprise all activities and processes associated with the flow and transformation of goods from the raw material stage through the end user [1]. The supply chain is related to all business processes of organizations. Human resources, technology, business structure, and resources are an inseparable whole with the concept of supply chain in this structure starting from the supplier to the customer. Sup-

Ertugrul Ayyildiz

eayildiz@yildiz.edu.tr

Alev Taskin Gumus ataskingumus@gmail.com

1 Department of Industrial Engineering, Yıldız Technical University, Y1ldız Campus, 34349 Istanbul, Turkey ply chain management is the optimization of all processes on the processes of a product or service from the manufacturer to the consumer. This optimization means increasing customer and supplier satisfaction while minimizing costs. Supply chain management, which was previously seen as a part of enterprise resource planning (ERP), has recently been recognized as a discipline in an international field. Supply chain management is very important as it improves customer service, reduces inventory costs and planning, and operating expenses, shortens decision-making processes, and increases competitiveness as a result of all this.

In the supply chain, all the elements that create the chain must be integrated. In the processes from the supplier to the customer, multiple functions fulfill certain tasks in line with certain needs. Supply chain management has some important fundamental phases. Managing requests and orders; constitutes the first part of the said stages. Active order management should be put into practice to meet the orders received by the customers completely and smoothly. The process of buying: it covers the supplying of all products and materials necessary 
for production in a fast, high quality, and effective manner. The planning process: it covers the most accurate planning of the production process included in the activities of the enterprise together with the cost calculations. The production process draws attention as the most important process in the supply chain. This process is very important, especially for organizations. It is important to convert the purchased material to the product with the most accurate tools in line with the desired time and quality criteria. Production stands out as an action to increase the quantity and benefits of products and services, in general. Inventory management process: it covers the determination of inventory levels following the production plans of all products and services owned by the organization. It also includes proper inventory management. The warehouse management process:it is closely related to inventory management. Planning and managing processes such as managing how and in what amount of inventories that are designed as a result of inventory management, storage of finished products, keeping these products ready for shipment are defined within the scope of warehouse management. Shipment process: it includes the process of taking the finished products from the warehouse ready for sale and delivering them to the customer.

Nowadays, when the global competition has reached its peak, making a profit is not only through purchasing but also as a process that occurs when purchasing and producing. Therefore, to companies to maintain continuity, they should make the right decisions on chainrings, make analyses and developments. Providing the coordination and control of all the business processes will provide efficiency throughout the chain, and will provide easy access to goals such as profitability and customer satisfaction. At this point, it is a strategic requirement for companies to give importance to supply chain management and to work in this direction to increase the performance of organizations significantly.

The concept of globalization has forced organizations to operate in a competitive environment that is constantly changing [2]. Accordingly, companies should develop strategies to achieve competitive advantages. Organizations must establish their developed strategies on operating their systems with the highest efficiency and effectiveness and at the same time ensuring maximum customer satisfaction [3]. One of the things that need to be done to increase productivity is the determination of performance metrics. Strategies to support productivity are developed based on determining performance metrics [4]. Companies analyze the metric that develops depending on the sectors they are in, create the workflow, and follow the flows with the awareness of competitive conditions. Therefore, performance measurement is also important in terms of follow-up, tactical, operational, planning, and control [5].

The problem of supply chain performance evaluation is an area that has been handled for many different researchers for a long time and has not become outdated. It can be said that a balanced scorecard and its extensions are the most frequently used method in supply chain performance evaluation. However, many studies that use the Supply Chain Operations Reference (SCOR) method as much as a balanced scorecard can be observed in supply chain performance evaluation in the literature. The prominent of these can be summarized as follows. Wang et al. adopt the SCOR model to evaluate product characteristics, then use the analytic hierarchy process (AHP) to match product characteristics with supplier characteristics [6]. Wang et al. select the best supplier via the AHP method. They also use goal programming for manufacturing supplier selection [7]. Hwang et al. utilize the SCOR model with Level 3 metrics to evaluate the TFT-LCD industry in Taiwan. Regression analysis is used to show the reliability of the proposed method [8]. Chae develops key performance indicators (KPIs) for the supply chain management. Industry-oriented performance measurement model based on SCOR can be easily adapted for different sectors [9]. Raut et al. use SCOR level 1 metrics as criteria for multi-criteria decision-making methodology. They use both AHP and data envelopment analysis for supplier selection [10]. Lu et al. develop a performance evaluation model for humanitarian supply chains. 26 different SCORbased metrics are eliminated and 14 metrics are proposed for performance evaluation [11]. Essakly et al. consolidate technology applications and define performance metrics to evaluate supply chain performance [12]. Lima Junior and Carpinetti develop a performance evaluation system based on SCOR via adaptive network-based fuzzy inference systems (ANFIS) methodology [13].

In this paper, we focus on performance evaluation of the supply chain. The SCOR model, which is frequently used in supply chain performance measurement, does not contain the requirements of supply chains for the digital age. For this reason, the performance measurement model in the literature needs to be updated considering the needs of the digital age. In this study, unlike the SCOR models in the literature, new metrics are added into the model and thus the novel SCOR 4.0 model is proposed. An effective performance measurement methodology for supply chains is presented with the proposed SCOR 4.0 model. We improve SCOR with newly two level 1 metrics to meet globalizing the world's requirement. The performance evaluation model is structured as a three-level hierarchical structure to evaluate the supply chain. We handle problems as a multi-criteria decision-making problem. This study presents the level 1 and their level 2 and level 3 metrics for supply chain performance evaluation problem, gains opinions from experts, uses hybrid Best worst method and Pythagorean fuzzy AHP method to determine the weights of metrics and finally evaluates oil supply chain as a case study. 
The rest of the paper organized as follows: the next section gives the traditional SCOR model and proposed a SCOR 4.0 model. Best worst-integrated Pythagorean fuzzy AHP methodology is presented in the third section. The fourth section presents the real case application for the oil supply chain of the proposed methodology. Lastly, the conclusions and future recommendations are given in the last section.

\section{The SCOR 4.0 model}

\section{SCOR model}

In 1996, the Supply Chain Council (SCC) developed the SCOR model to assist firms to improve the effectiveness of their supply chains and to provide a process-based approach to supply chain management [14].

SCOR is a combined benchmarking, business process reengineering, and best practices and it also references a model that is intended to be an industry standard. Standard means how they perform, how they are configured, the way of process' interaction, and the requirements on staff who operating the process. To be more easily and effectively applied in the industry, the current version of SCOR has been reached by continuously updating and detailing. This model is the first reference model in the world, which has been recognized as the cross-industry standard for supply chain management.

There are four basic components in the SCOR reference model. These four components are described below:

- Performance: standard metrics for defining process performance and defining strategic objectives,

- Processes: standard definitions of process relations and management processes,

- Practices: management applications that provide better process performance,

- People: defines the standard for the people's skills needed to perform better supply chain processes.

The performance part of the SCOR reference model consists of two types of components: performance attributes and metrics. Performance attribute is a group of metrics that used to explain a strategy. An attribute is used to determine the strategic direction and cannot measure itself. Metrics measure the ability to achieve these strategic directions. A metric is a standard for measurement. SCOR recognizes five key supply chain performance attributes. It can be seen in Fig. 1.

Reliability: the right distribution of the supply chain to the right customer at the right place, at the right time, in the right shape, and the package, in the right amount, with the right documents.
Flexibility: the ability of the supply chain to respond to changes in the market to maintain or enhance its competitiveness.

Responsiveness: delivery speed of supply chain's products to customers.

Cost: all costs related to the management of the supply chain.

Assets: efficiency of managing the supply chain organization's assets to meet demand.

Supply Chain Council recommends supply chain scorecards to contain at least one metric for each performance attribute to ensure balanced decision making and governance [15]. Performance evaluation in the supply chain starts from the storage of goods, materials, and information from the point of origin to the point end customer. Efficient and lowcost processes need to be implemented to fulfill the objective of the supply chain.

\section{SCOR 4.0 model and performance metrics}

As can be seen from Fig. 1, there are only five main attributes that must be directly considered for supply chain performance evaluation: reliability, flexibility, responsiveness, cost, and assets. These performance attributes are determined based on the general SCOR model considering the needs of the traditional supply chain. SCOR model one of the best models to describe supply chain activities in operations management for research and practice alike. It gives the results to help decision makers to pretend and analyze the supply chain [16].

However, there are radical changes in the structure of supply chains as well as developing technology in today's information age. Renewal of supply chains with developing technology is important in keeping up with the age. In this context, new metrics should be taken into consideration in evaluating the performance of supply chains. All dimensions of the supply chain should be considered together with these new metrics while determining the performance of the supply chain. For this reason, the new requirements of the supply chain should be determined accurately and new metrics should be carefully determined taken into consideration new requirements and integrated into the SCOR model. Therefore, Digital Technology and Information Systems considered as a new two metrics in the novel SCOR model are proposed in this paper. The novel SCOR model that we called as a SCOR 4.0 is a structured three-level hierarchical structure to evaluate supply chain performance. The main and their inner metrics that establishing SCOR 4.0 are identified by the literature review and then appropriate factors are determined by experts. The experts are determined by considering their experiences in supply chain operations. The SCOR 4.0 model and its inner levels can be seen in Fig. 2. 
Fig. 1 SCOR performance attributes

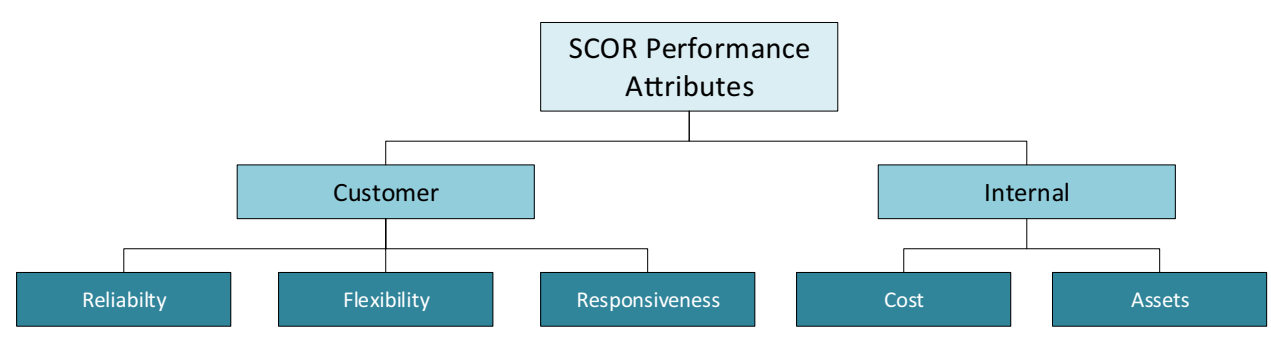

The SCOR 4.0 model consists of seven different level1 metrics. "Digital Technology" and "Information Systems" are new metrics added to the traditional SCOR model to meet globalizing the world's need.

\section{Reliability}

"Reliability" is related to the right distribution of the supply chain to the right customer at the right place, at the right time, in the right shape and the package, in the right amount, with the right documents. It consists of three level 2 metrics that have three inner metrics in the proposed SCOR 4.0 model.

First level 2 metric is "Quantity" that associated with quantitative values of the supply chain's reliability. "Maximum Delivery Amount" refers to the maximum amount of products that can deliver to end customer [17]. "Maximum Delivery Time" is related to the latest lead time that the supply chain can compensate. "Average Delivery Time" means of the delivery time from raw material to end customer.

The metric that deals with accuracy in the processes of the supply chain is "Accuracy". "Delivery Performance" measures the performance of the supply chain to its lead time and promised quantity for each stage of the supply chain [18]. Accuracy in the documentation is also important for the supply chain. Any difference between the document and real physical goods may cause an extra cost for each component of the supply chain. "Document Accuracy" is calculated as a percentage of errors due to the discrepancy between physical products and the document. The discrepancy may result from the incorrect information or transaction updated with the wrong document [19]. "Order Fulfillment" starts with the order received from the customer and finish with the delivery of the product to the customer [20]. This metric measures the percentage of successful order.

The last level 2 metrics of "Reliability" is "Quantity". Quantity consists of three level 3 metrics as "Damage Free Orders", "Faultless Installation" and "Fill Rate". "Damage Free Orders" can be expressed as the ratio of the number of orders received without damage to the total number of orders processed in a given period [21]. "Faultless Installation" is calculated using the Number of faultless installations and the number of installation [22]. The ratio between two numbers is important to measure the "Reliability" of the supply chain.

\section{Flexibility}

The agility of responding to market changes to gain and/or maintain a competitive advantage of a supply chain is called a "Flexibility".

The first metric that related to "Flexibility" is "Production" flexibility. "Plan Flexibility" refers to the ability to change in the production or transportation plan of the supply chain. "Production Flexibility" means to respond quickly to change in customer requirements with the minimum cost [23]. "Supply Chain Adaptability" is associated with the adaptability of the supply chain to changes in any stage of the supply chain [24].

Flexibility on the "Delivery" is the ability to change both the quantity and date of delivered products. Backlogging is a classical example of flexibility [25]. "Response Time" is the maximum response time occurring in any stage of the supply chain to the changes [26]. The supply chain should react purposefully and appropriately for changes. "Quantity Change in Supply", "Quantity Change in Deliver" means a positive or negative shift on the number of products for supply and delivery, respectively.

The last level 2 metric is "Risk". Risk on the "Production" is that the products cannot be produced effectively and efficiently with the changing design of the customers [27]. Risk on the "Return" means the risk of the customer returning the product. Risk on the "Delivery" means interrupting the delivery amount.

\section{Responsiveness}

"Responsiveness" can be summarized as a speed of supply chain to provide products for customers. There are two different inner metrics for the "Responsiveness" in the proposed SCOR 4.0 model.

"Cycle Time" has great importance for every component of the supply chain. Therefore, it is integrated into the proposed SCOR 4.0 model as a Level 2 metric. "Delivery Cycle Time" is the period that starts with the order and ends with the delivery of the product. "Source Cycle Time" measures the time required for sourcing the products from sources such as suppliers. "Delivery Retail Cycle Time" means cycle time for retailers. 
Fig. 2 SCOR 4.0 performance metrics

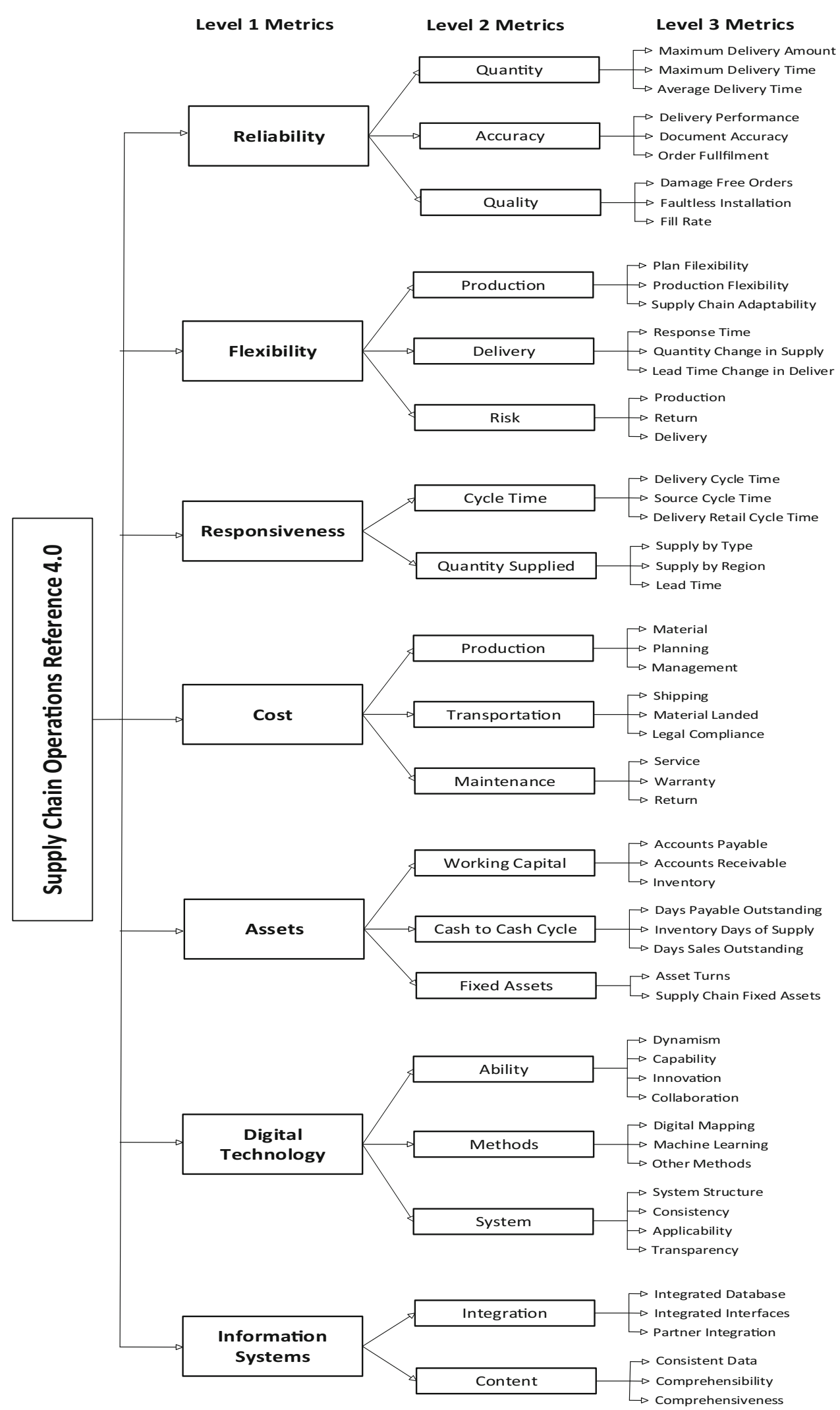


"Quantity Supplied" is examined in three Level 3 metrics. "Supply by Type" refers to the number of products or material types that supply chain supplies. "Supply by Region" is related to the region of suppliers. "Lead Time" is the average delivery time of orders [5].

\section{Cost}

Cost metrics include all costs related to the supply chain. Different factors affect the cost of the supply chain. As a result of developing technologies and needs, it has been inevitable to add logistics costs to traditional product costs. It represents the sum of all costs that occur in supply chain operations.

First Level 2 metric's inner level of "Cost" is "Production" cost. This cost represents all the expenses related to producing the product to serve the customer. "Production" cost includes material, labor, and machine cost [28]. "Planning" cost consists of all costs associated with planning. These are costs such as salaries of personnel, documentation costs. "Management" cost includes the salary of supply chain managers and personnel.

Transportation costs are the costs that arise from leaving the product (goods or services) to the customer until it reaches the customer. These costs depend on variables such as weight, volume, type of product, and distance to be transported [29]. "Shipping" cost is the physical costs that arise in the transportation of the product [30]. Some classical examples of these costs are car rental, gasoline cost, and driver cost. "Material Landed" cost includes purchasing costs, freight, and other costs such as transportation insurance, delivery product to the location of use [31]. It can be summarized as the total cost associated with presenting the purchased materials or products to the place where they were purchased and used. "Legal Compliance" costs consist of costs caused by legal obligations such as import-export taxes and transportationrelated taxes.

"Maintenance" cost includes three Level 3 metrics. "Service" costs are the cost related to serving products or material to the customer for each stage of the supply chain [32]. "Warranty" cost includes costs that occur from warranty agreements. "Return" cost consists of the total cost of the returned items due to planning errors, supplier quality, production, management order, and delivery errors [31].

\section{Assets}

The metric of "Assets" represents the effectiveness of the supply chain in managing assets to support demand satisfaction. This includes the management of all assets [33].

"Working Capital" plays a key role in all supply chain components. It consists of funds that are linked to the production factors during the period from the start of the production of the products to the income. It is used to cover the expenses to be made until operating income is obtained [34]. "Working Capital" includes three different Level 3 metrics. "Accounts Payable" represents the money that a supply chain owes to external factors. It also means the business department of the supply chain that is responsible for paying debts to external factors and other creditors [35]. "Accounts Receivable" means the money caused by goods or services delivered or used by a company that is not from the supply chain but not yet paid by customers. It can be summarized as the money that customers owe in shopping with credit. "Inventory" refers to the total money or product inventory of the supply chain.

"Cash to Cash Cycle" is another Level 2 metric for "Assets". It refers to the time it takes for the production process that companies start with the cash payment day for raw material until the day they collect their receivables [36, 37]. "Cash to Cash Cycle" includes three different Level 3 metrics. "Days Payable Outstanding" shows the average number of days the supply chain has paid its debts, invoices, and suppliers [38]. "Inventory Days of Supply" specifies how many days the inventory amount will be sufficient in a certain period. It also means how fast the supply chain has turned into sales. "Days Sales Outstanding" is the average number of days that the supply chain will get money from selling a product.

"Fixed Assets" consist of two level 3 metrics as "Asset Turns" and "Supply Chain Fixed Assets". "Asset Turns" measures the value of a supply chain's sales or income based on the value of the supply chain's assets. It can be used as one of the indicators that show the efficiency of the supply chain [39]. "Fixed Assets" presents assets that will not be sold to customers, cannot be converted into cash quickly, and are used to provide economic benefits using them in the production or service process in the long term.

\section{Digital technology}

The performance of "Digital Technology" is measured using three different Level 2 metrics. The first one of them is "Ability". This metrics is related to the skills and proficiency of the supply chain. It consists of four Level 3 metrics. "Dynamism" refers to the ability of the supply chain to react autonomously to changing external conditions. Finding a suitable solution by adapting the supply chain to changes is important for this metric [40]. "Capability" expresses the capability of the supply chain to cope with possible problems. Capabilities of the supply chain ensure sustainable success in the near future to organizations [41]. Identification, development, and mobilization are some of the sub capabilities of supply chains [42]. "Innovation" is playing a key role in the reconfiguration and renovation of the supply chain. It supports the supply chain in the processing of evolving through changes [43]. "Collaboration" refers to fully digitalization of the internal and inter-agency distribution process and strong collabora- 
tion with customers and external service providers form the basis for developing autonomous and self-optimization capabilities [43].

Second level 2 metrics of "Digital Technology" is "Methods" that have three level 3 metrics. "Digital Mapping" is a process in that real data of physical reality is formatted as a virtual image. It is important to perform data analysis to increase productivity and to take place in the digital map for supply chains. Digital maps help the supply chain to easily access its elements [44]. "Machine Learning" techniques provide algorithms to elements of the supply chain that use existing data to perform forecasting, clustering, and classification [45]. "Other Methods" means usage of other methods based on Digital Technology such as mobile devices [46] and automated monitoring [47].

"System" is the last Level 2 metric of this Level 1 metric. "System Structure" associated with computers, mobile devices using in the supply chain. It includes their integration and computing capacity to perform better digitalization infrastructure [48]. "Consistency" is related to the consistent digitalization of the supply chain. To deal with the complexity of Digital Technology used in the supply chain, digital technologies should be used consistently for each stage of the chain [49]. "Applicability" refers to the applicability of Digital Technology to each stage of the supply chain. "Transparency" is the ability to track the movements of products, parts, and/or components from the manufacturer to the final destination (customer). The aim is to improve and strengthen the supply chain by enabling easy access to product-related data for all stakeholders, including the customer [50].

\section{Information system}

"Integration" and "Content" are an important component of "Information Systems". "Integrated Database", "Integrated Interfaces" and "Partner Integration" are Level 3 metrics of the "Integration" metric. "Integrated Database" means integrating different data sources from different stages of the supply chain and creating the main data source from these sources [51]. The supply chain should provide shared and integrated interfaces to prevent discontinuities on information flow. Therefore, "Integrated Interfaces" refers to interfaces between departments/organizations, user/product interfaces, and interfaces of human-machine systems [43, 52]. "Partner Integration" means integration between customers, suppliers, transporter, and other external partners of the supply chain to achieve a digital ecosystem.

Three level 3 metrics create "Content". "Consistent Data" means end-to-end data or information flows from multiple sources to provide real-time analytics [43, 47]. "Comprehensibility" associated with an easy understanding of the Information Systems used. "Comprehensiveness" means

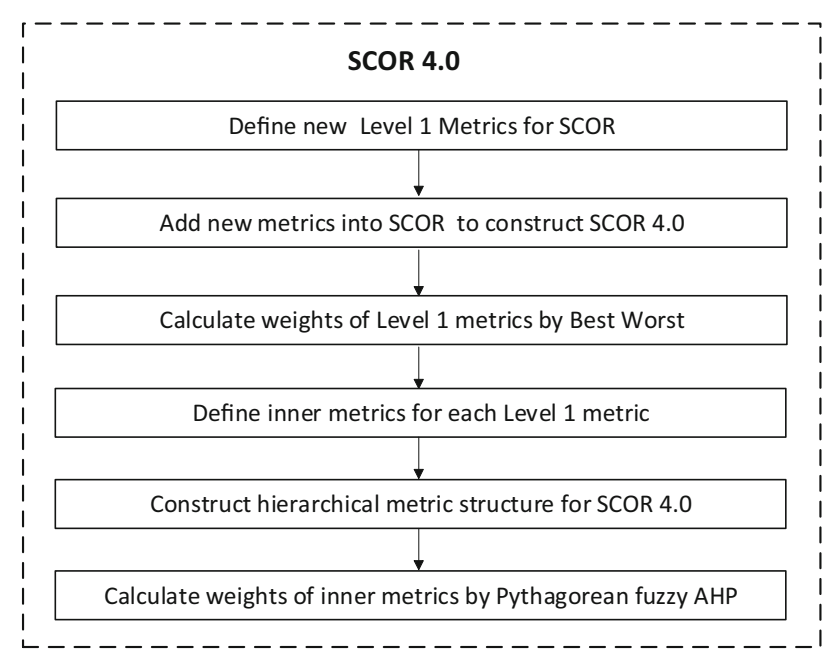

Fig. 3 The proposed methodology

Information Systems used in all relevant stages of the supply chain.

\section{Theoretical background and proposed methodology}

In this study, a three-level hierarchy is established with the proposed novel SCOR 4.0 model attributes suitable supply chain performance evaluation in the globalizing world as model criteria. Then, the experts' evaluations for level 1 metrics are gained and used in the Best worst method to determine the importance weights of level 1 metrics for the oil sector supply chain. Then, the importance weights of level 2 and level 3 metrics are determined via Pythagorean fuzzy AHP methodology. Subsequently, the results are analyzed and interpreted. The sensitivity analysis is performed to show the reliability of the proposed methodology. Finally, conclusions and future direction of this work are given. Figure 3 shows the levels of the proposed methodology.

\section{Best worst method}

Researchers and theoreticians have focused on decisionmaking problem and its extensions over the years. The number of applications of these problems for public and private sectors is increasing day by day. Researchers handle these problems and solve them by developing different decision support models such as optimization and multicriteria decision making. These problems may involve both quantitative and qualitative factors. The decision-making problems usually include more than one criteria are called as multi-criteria decision-making problem. The most used multi-criteria decision making in the literature can be classified into three titles: scoring, outranking, and pairwise

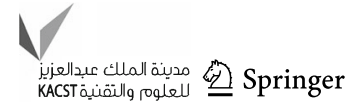


comparison. Analytic hierarchy process (AHP), analytic network process (ANP), the decision making trial and evaluation laboratory (DEMATEL) are most famous multi-criteria decision + making methods based on the pairwise comparison [53]. Pairwise comparisons on criteria or alternatives pose a challenge for decision makers (DMs) because they may not have the ability to make consistent decisions on a large number of criteria/alternative [54]. To handle this challenge, Razei proposed Best worst method (BWM) based on the structured pairwise comparison scheme [55]. BWM is a method based on choosing the best criteria and the worst criteria and comparing these criteria with other criteria [56]. DMs do not need to perform all pairwise comparisons among all criteria, with the BWM method. It is sufficient for DMs to compare only the best and worst criteria with other criteria. For this reason, BWM is superior to AHP with less comparison time and higher reliability of prioritization results [54]. The steps of BWM are given following [57].

Step 1: Determine the criteria that will be evaluated $\left(C_{1}, C_{2}, \ldots, C_{n}\right) . n$ represents the number of criteria.

Step 2: Determine the most important (best) and least important (worst) criteria. There is no comparison performed at this step.

Step 3: Determine the level of importance of the most important criterion over all the other criteria. Comparison is performed using a number between 1 and 9.1 means there is equal importance between two criteria. 9 means that one criterion is absolutely important than the other. Construct the best-to-others vector:

$A_{B}=\left(a_{B 1}, a_{B 2}, \ldots, a_{B n}\right)$ where $a_{B j}$ shows the level of importance of the most important criterion $B$ over criterion $j$. Indicate that $a_{B B}$ must be 1 .

Step 4: Determine the level of importance of all the criteria over the least important criterion by between 1 and 9 . Construct the Others-to-Worst vector:

$A_{w}=\left(a_{1 W}, a_{2 W}, \ldots, a_{n W}\right)^{\mathrm{T}}$ where $a_{j W}$ shows the level of importance of the criterion $j$ over the least important criterion $W$. Indicate that $a_{W W}$ must be 1 .

Step 5: Find the optimal weights of criteria $\left(w_{1}^{*}, w_{2}^{*}, \ldots, w_{n}^{*}\right)$. For each pairwise comparison of $\frac{w_{B}}{w_{j}}$ and $\frac{w_{j}}{w_{W}}$, the value of $\frac{w_{B}}{w_{j}}=a_{B j}$ and $\frac{w_{j}}{w_{W}}=a_{j W}$ are determined in Step 3 and Step 4, respectively. The goal is to determine the optimal weights of the criteria to make maximum absolute differences $\left|\frac{w_{B}}{w_{j}}-a_{B j}\right|$ and $\left|\frac{w_{j}}{w_{W}}-a_{j W}\right|$ for all $\mathrm{j}$ is minimized, at this step. Add nonnegativity constraints (2) and the constraint for the sum of all criteria weights (3) and solve the following mathematical model:

$$
\underbrace{\min \max _{j}\left\{\left|\frac{w_{B}}{w_{j}}-a_{B j}\right|,\left|\frac{w_{j}}{w_{W}}-a_{j W}\right|\right\}}_{j}
$$

subject to

$w_{j} \geq 0, \quad$ for all $j$

$\sum_{j=1}^{n} w_{j}=1$

This mathematical model can be expressed as following model:

$\min \zeta$

subject to:

$\left|\frac{w_{B}}{w_{j}}-a_{B j}\right| \leq \zeta, \quad$ for all $j$
$\left|\frac{w_{j}}{w_{W}}-a_{j W}\right| \leq \zeta, \quad$ for all $j$

Eqs. (2) and (3)

The optimal weights of criteria $\left(w_{1}^{*}, w_{2}^{*}, \ldots, w_{n}^{*}\right)$ and $\zeta$ are obtained by solving the mathematical model. The value of $\zeta$ shows the consistency of the proposed model. As the value increases, it is concluded that the comparisons are less reliable and their consistency is weak, and as the value decreases, the consistency and reliability of comparisons are high.

\section{Pythagorean fuzzy sets}

Fuzzy logic was first introduced to the literature by Zadeh [58]. The theory is suitable for subjective judgment and qualitative assessment in the evaluation processes of decisionmaking problems [59]. The logic focuses on the rationality of uncertainty due to ambiguity. The linguistic approach is an effective method to solve uncertainty in information [60]. Such information can be formalized as a fuzzy set [61].

Pythagorean fuzzy sets are presented by Yager and applied to many real-life problems [62]. Wang and Li extend power Bonferroni mean operator with Pythagorean fuzzy numbers and present novel multi-criteria decision-making methodology [63]. Li et al. propose an aggregation operator to address the interaction among membership and non-membership grades of the Pythagorean fuzzy numbers [64]. Wang and Li develop novel operators for dealing with interval-valued Pythagorean fuzzy information, such as continuous intervalvalued Pythagorean fuzzy-ordered weighted quadratic averaging operator and its extensions [65]. Gul and Yucesan evaluate hospital service quality via Pythagorean fuzzy AHP and Technique for Order Preference by Similarity to Ideal Solution (TOPSIS) [66]. Gul et al. develop a risk assessment model based on Pythagorean fuzzy VlseKriterijumska Optimizacija I Kompromisno Resenje (VIKOR) for mine 
industry [67]. Ozkan et al. evaluate blockchain risk by Pythagorean fuzzy AHP [68]. Karasan et al. analyze the risks of autonomous vehicle driving systems via Pythagorean fuzzy AHP [69]. Yildiz et al. determine the best location for an automated teller machine (ATM) by Pythagorean fuzzy AHP-integrated Pythagorean fuzzy TOPSIS methodology [70].

Pythagorean fuzzy sets are developed based on intuitionistic fuzzy sets [71]. Pythagorean fuzzy sets are also as a generalization to the intuitionistic fuzzy sets and address the uncertainty in some conditions where intuitionistic fuzzy sets cannot. Intuitionistic fuzzy sets and Pythagorean fuzzy sets are defined with membership and non-membership degrees. While Zadeh's fuzzy set theory includes only the degree of membership defined in the $[0,1]$ range, Atanassov adds a non-membership degree to define the degree of membership in the intuitionistic fuzzy sets [72]. Both the degree of membership and non-membership take value in the $[0$, 1] range. Unlike the traditional fuzzy sets, the sum of the degree of membership and non-membership does not have to be 1 in intuitionistic fuzzy sets. But, the sum of the degree of membership and non-membership has to be smaller than 1 in intuitionistic fuzzy sets. Yager introduces another class of membership grades as Pythagorean membership grades to develop a general theory of membership grades. Yager shows that the membership grades of the intuitionist fuzzy sets can be generalized to be based on a more general class of negations then the case where nonmembership $=1-$ membership. Pythagorean membership grades are greater than the space of intuitionistic membership grades [72]. Unlike the intuitionistic fuzzy sets, the sum of membership and non-membership degrees can exceed 1, but the sum of squares cannot So if the problem involves more uncertainty, Pythagorean fuzzy sets are more powerful to handle uncertainty then intuitionistic fuzzy sets [73, 74].

Definition 1 A Pythagorean fuzzy set can be shown as $\tilde{\boldsymbol{P}}$ in the following equation [75]:

$\widetilde{P} \cong\left\{x, \tilde{P}\left(\mu_{\tilde{p}}(x), v_{\tilde{p}}(x)\right) ; x \in X\right\}$,

where $\boldsymbol{X}$ is a fixed set in the function. $\mu_{\tilde{p}}(x): X \mapsto[0,1]$ and $v_{\tilde{p}}(x): X \mapsto[0,1]$ defines the degree of membership and degree of non-membership of the element $x \in X$ to $\tilde{P}$, respectively.

$0 \leq \mu_{\tilde{p}}(x)^{2}+v_{\tilde{p}}(x)^{2} \leq 1 ; \quad x \in X$.

The indeterminacy's degree is calculated by the following equation [76]:

$\pi_{\tilde{p}}(x)=\sqrt{1-\mu_{\tilde{p}}(x)^{2}-v_{\tilde{p}}(x)^{2}}$.

\section{Interval-valued Pythagorean fuzzy sets}

While experts are evaluating the criteria and alternatives in the decision process, instead of giving crisp numbers, they can use interval numbers to better reflect the uncertainty. In this paper, interval fuzzy numbers are applied to deal with the vagueness better. The preliminaries for the interval-valued Pythagorean fuzzy numbers are given as follows [77-79].

Definition 2 An interval-valued Pythagorean fuzzy set $A$ defined in $\boldsymbol{X}$ is given as [78, 79]:

$A=\left\{x\left[\mu_{A_{\mathrm{L}}}(x), \mu_{A_{\mathrm{U}}}(x)\right],\left[v_{A_{\mathrm{L}}}(x), v_{A_{\mathrm{U}}}(x)\right] ; x \in X\right\}$,

where

$$
\begin{aligned}
0 & \leq \mu_{A_{\mathrm{L}}}(x), \mu_{A_{\mathrm{U}}}(x), v_{A_{\mathrm{L}}}(x), v_{A_{\mathrm{U}}}(x) \\
& \leq 1, \quad \text { and } \quad\left(\mu_{A_{\mathrm{L}}}(x)\right)^{2}+\left(v_{A_{\mathrm{L}}}(x)\right)^{2} \leq 1 x \in X .
\end{aligned}
$$

Similar to Pythagorean fuzzy sets, corresponding to interval-valued membership values, its hesitation interval relative to $A$ is given as:

$$
\begin{aligned}
\pi_{\mathrm{A}}(x)= & {\left[\pi_{A_{\mathrm{L}}}(x), \pi_{A_{\mathrm{U}}}(x)\right] } \\
= & {\left[\sqrt{1-\left(\mu_{A_{\mathrm{U}}}(x)\right)^{2}-\left(v_{A_{\mathrm{U}}}(x)\right)^{2}},\right.} \\
& \left.\sqrt{1-\left(\mu_{A_{\mathrm{L}}}(x)\right)^{2}-\left(v_{A_{\mathrm{L}}}(x)\right)^{2}}\right]
\end{aligned}
$$

If for every $x \in X, \mu_{A}(x)=\mu_{A_{\mathrm{L}}}(x)=\mu_{A_{\mathrm{U}}}(x)$ and $v_{A}$ $(x)=v_{A_{\mathrm{L}}}(x)=v_{A_{\mathrm{U}}}(x)$ then interval-valued Pythagorean fuzzy set transforms to Pythagorean fuzzy sets. For an interval-valued Pythagorean fuzzy set $\mathrm{A},\left[\mu_{A_{\mathrm{L}}}(x), \mu_{A_{\mathrm{U}}}(x)\right]$, $\left[v_{A_{\mathrm{L}}}(x), v_{A_{\mathrm{U}}}(x)\right]$ is called an interval-valued Pythagorean fuzzy number.

The score function of an interval-valued Pythagorean fuzzy number $\alpha=[a, b],[c, d]$ is defined as:

$S(\alpha)=\frac{a^{2}+b^{2}-c^{2}-d^{2}}{2}$,

where $(\alpha) \in[-1,1]$. But, sometimes, it has been observed that this function is unable to rank the intervalvalued Pythagorean fuzzy numbers. For instance, if we take $\alpha_{1}=[0.2,0.4],[0.2,04] \alpha_{2}=[0.5,0.6],[0.5,06]$ to be two interval-valued Pythagorean fuzzy numbers, then by Eq. (13), we get $S\left(\alpha_{1}\right)=S\left(\alpha_{2}\right)=0$. Thus, it is unable to find the best among them. For resolving it, there is another function called as the accuracy function for an interval-valued Pythagorean fuzzy number $\alpha$ which is defined as follows [77]:

$h(\alpha)=\frac{a^{2}+b^{2}-c^{2}-d^{2}}{2}$ where $H(\alpha) \in[0,1]$. 


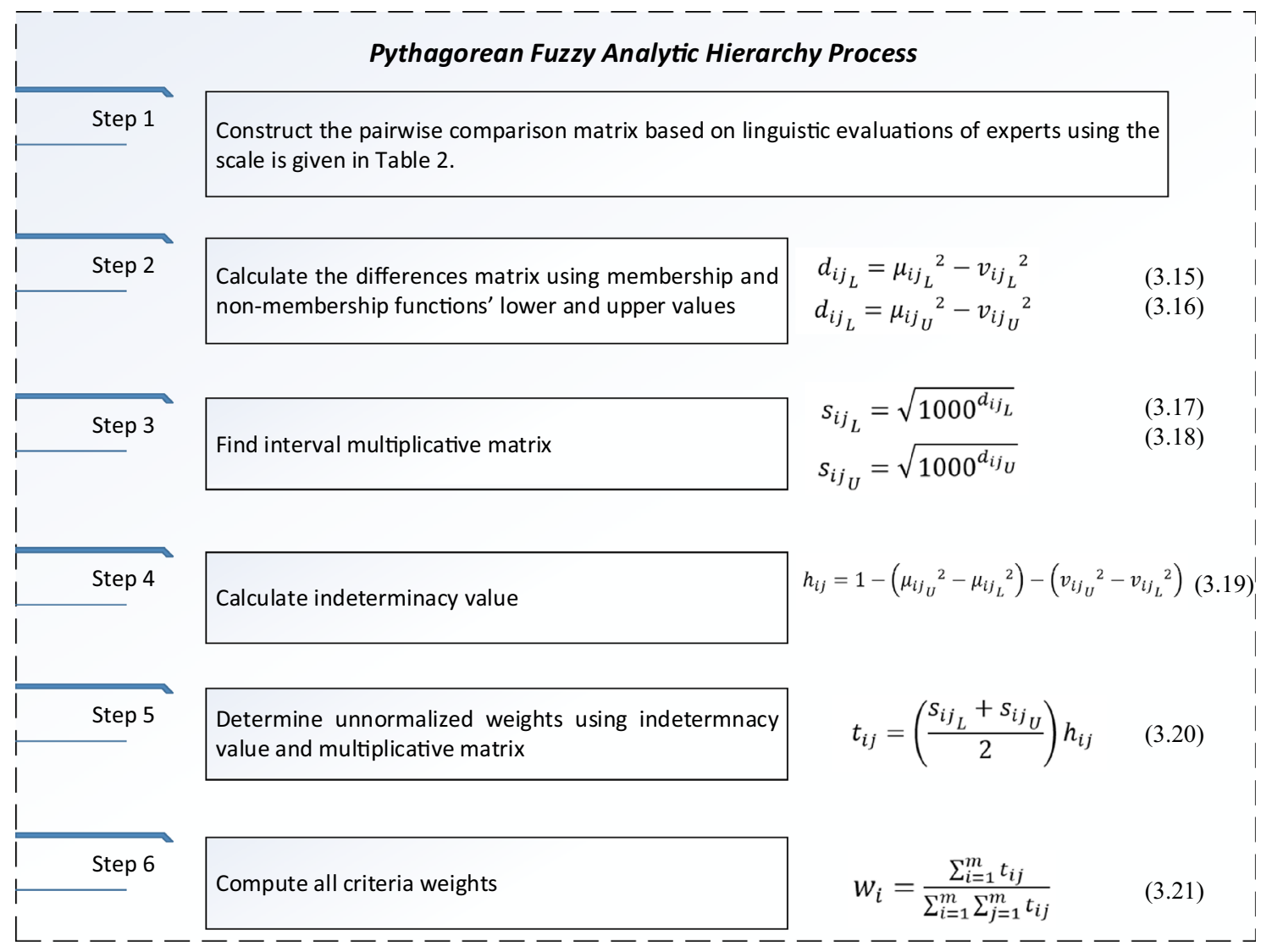

Fig. 4 The steps of Pythagorean fuzzy AHP method

Now, based on these two functions, a comparison method for any two interval-valued Pythagorean fuzzy numbers $\alpha$ and $\beta$ is defined as follows:

Definition 3 Let $\alpha$ and $\beta$ be any two IVPFNs. Then

(i) If $S(\alpha)<S(\beta)$, then $\alpha \prec \beta$.

(ii) If $S(\alpha)>S(\beta)$, then $\alpha \succ \beta$.

(iii) If $S(\alpha)=S(\beta)$,

- If $S(\alpha)<S(\beta)$, then $\alpha \prec \beta$.

- If $S(\alpha)>S(\beta)$, then $\alpha \succ \beta$.

- If $S(\alpha)=S(\beta)$, then $\alpha \sim \beta$.

\section{Pythagorean fuzzy AHP}

AHP is used for solving multi-criteria decision-making (MCDM) problems. AHP is based on criteria and alternatives' pairwise comparison [70]. AHP receives opinions from experts [80]. Even if the method receives information from experts, sometimes it does not reflect the thinking style of people exactly [81]. Fuzzy logic can be used in these situations. PF sets can be used with the AHP method to eliminate uncertainty and ambiguity caused using net values in AHP.
Figure 4 shows the steps of Pythagorean fuzzy AHP methodology.

Examine the consistency of the pairwise comparison matrices. To find the consistency ratio (CR) of a matrix use crisp values proposed from Saaty, first find the matrix consistency index (CI) using [82]:

$\mathrm{CI}=\frac{\lambda_{\max }-n}{n-1}$.

Then, calculate the CR using:

$\mathrm{CR}=\frac{\mathrm{CI}}{\mathrm{RI}}$.

$\lambda_{\max }$ is the largest or principal eigenvalue of the A decision matrix of pairwise comparison. Random index (RI) depends on matrix order $(n)$ and is calculated using the table proposed by Saaty. If CR is equal or less than 0.1, then the matrix is considered acceptable [82]. 
Table 1 Expert group evaluation for level 1 metrics

\begin{tabular}{lllll}
\hline Expert group & Best & Worst & $A_{B}$ & $A_{w}^{\mathrm{T}}$ \\
\hline EG 1 & Reliability & Flexibility & $(1,6,4,2,4,5,3)$ & $(6,1,3,5,3,2,4)$ \\
EG 2 & Information Systems & Assets & $(2,3,3,4,5,3,1)$ & $(4,3,3,2,1,3,5)$ \\
EG 3 & Information Systems & Flexibility & $(2,4,3,2,3,3,1)$ & $(3,1,2,3,2,2,3)$ \\
\hline
\end{tabular}

\section{A numerical application for oil supply chain}

Oil products are an indispensable resource in meeting energy needs in today's world. With the development of technology in the last years, the need for oil products is increasing day by day. More than a third of the energy currently used by the world is based on oil [83]. The negative effects of petroleum products on the environment and human life, in which the number of users increases in all areas of life, are also negligible. The main priorities of the oil sector's supply chain management activities are the transportation of petroleum oil and other inputs to be distributed from local or international sources, storage, and transportation to the endpoints. These activities should be carried out at the most affordable costs, on time, following international standards and legal regulations, by adhering to quality assurance, without harming the environment and under technical safety rules.

There is limited literature on companies' selection of suppliers and evaluation methods via multi-criteria decisionmaking techniques [84]. In this study, the new SCOR 4.0 model that involved the needs of the supply chain in the globalizing world is proposed. In the proposed model, determining the importance levels of metrics is important for the managers of the supply chains. Managers should consider the importance of each metric when making decisions about the supply chain. Therefore, importance levels are determined for each level metric in the proposed model. An application is performed for the oil supply chain to verify the proposed model. The oil supply chain is one of the most important supply chains because of its complexity.

\section{Determination of weights of level 1 metrics by Best worst method}

First, three different expert groups are created to take opinions about performance evaluation of supply chains: academicians, managers, and third party logistics. In the first group (EG 1), opinions of academicians from different departments related to the supply chain of three different universities are collected. The second group (EG 2) includes managers from both suppliers and retailers. The last group (EG 3) is created to integrate the opinions of the managers of third party logistics companies, which play an active role in product supply and distribution. All experts work for sup-
Table 2 Weights of level 1 metrics

\begin{tabular}{lllll}
\hline Level 1 metric & EG 1 & EG 2 & EG 3 & Final weight \\
\hline Reliability & 0.342 & 0.180 & 0.164 & 0.228 \\
Flexibility & 0.047 & 0.120 & 0.073 & 0.080 \\
Responsiveness & 0.100 & 0.120 & 0.109 & 0.110 \\
Cost & 0.199 & 0.090 & 0.164 & 0.151 \\
Assets & 0.100 & 0.054 & 0.109 & 0.088 \\
Digital technology & 0.080 & 0.120 & 0.109 & 0.103 \\
Information systems & 0.133 & 0.316 & 0.273 & 0.241 \\
$\zeta$ & 0.057 & 0.044 & 0.055 & - \\
\hline
\end{tabular}

ply chain operations. Face to face interviews is conducted with experts to get their ideas on performance metric for oil sector's supply chain.

In the first step of the Best worst method, a questionnaire is applied to each expert group and they are asked to choose the best and worst Level 1 metrics given in Fig. 2. After determining the best and worst criteria, first, pairwise comparisons the best to the others are performed, then, pairwise comparisons the others to the worst are performed and given in Table 1.

The mathematical model given in Step 5 is applied to the comparisons obtained as a result of the survey conducted with each expert group and the weights of level 1 metrics and the value of $\zeta$ are obtained as in Table 2. Then, the average level 1 metric weights of all expert groups are calculated, and the final level 1 metrics weights are obtained as in Table 2.

As can be seen from Table 2, the value of $\zeta$ is calculated as less than 0.1 for all expert groups. Accordingly, it is possible to say that the comparisons of expert groups are consistent.

The importance weights of the seven level 1 metrics, Reliability, Flexibility, Responsiveness, Cost, Assets, Digital Technology, and Information Systems are calculated as $0.228,0.080,0.110,0.151,0.088,0.103$ and 0.241 , respectively. The most significant level 1 metric for oil sector supply chain is specified as the Information Systems with the importance of weight as a 0.228 . Reliability and Cost are also important level 1 metrics. Flexibility is the least level 1 metric for oil sector supply chain with a 0.080 according to results in this study. 
Table 3 Scale for the interval-valued Pythagorean fuzzy AHP evaluations

\begin{tabular}{lllll}
\hline Linguistic variables & \multicolumn{3}{l}{$\begin{array}{l}\text { Interval-valued Pythagorean fuzzy } \\
\text { numbers }\end{array}$} \\
\cline { 2 - 5 } & $\mu_{\mathrm{L}}$ & $\mu_{\mathrm{U}}$ & $v_{\mathrm{L}}$ & $v_{\mathrm{U}}$ \\
\hline Certainly low important (CL) & 0.0 & 0.0 & 0.9 & 1.0 \\
Very low important (VL) & 0.1 & 0.2 & 0.8 & 0.9 \\
Low important (L) & 0.2 & 0.35 & 0.65 & 0.8 \\
Below average important (BA) & 0.35 & 0.45 & 0.55 & 0.65 \\
Exactly equal (EE) & 0.1965 & 0.1965 & 0.1965 & 0.1965 \\
Average important (A) & 0.45 & 0.55 & 0.45 & 0.55 \\
Above average important (AA) & 0.55 & 0.65 & 0.35 & 0.45 \\
High important (H) & 0.65 & 0.8 & 0.2 & 0.35 \\
Very high important (VH) & 0.8 & 0.9 & 0.1 & 0.2 \\
Certainly high important (CH) & 0.9 & 1.0 & 0.0 & 0.0 \\
\hline
\end{tabular}

Table 4 Pairwise comparison of EG 1 for reliability

\begin{tabular}{llll}
\hline Reliability & Quantity & Accuracy & Quality \\
\hline Quantity & EE & BA & EE \\
Accuracy & AA & EE & AA \\
Quality & EE & BA & EE \\
\hline
\end{tabular}

\section{Determination of weights of level 2 and level 3 metrics by Pythagorean fuzzy AHP}

After determining the weights of level 1 metrics, the same expert groups are consulted; and they are asked to express their opinions in the weighting of the level 2 and level 3 metrics via questionnaire. Expert groups are first asked to evaluate all level 2 metrics. For this purpose, they use the linguistic variables in Table 3, and thus, pairwise comparison matrices for level 2 metrics are constructed. For example, the pairwise comparison matrix created by EG 1 for the Reliability is as shown in Table 4.

After level 2 metrics evaluations, the level 3 metrics pairwise comparisons of the related level 2 metrics are structured. For example, Table 5 shows the pairwise comparison matrix created according to the evaluations made by EG 2 for the level 3 metrics of the system level 2 metric. Besides, Table 6 shows the pairwise comparison matrix created according to
Table 6 Pairwise comparison of EG 3 for transportation

\begin{tabular}{llll}
\hline Transportation & Shipping & Material landed & $\begin{array}{l}\text { Legal } \\
\text { compliance }\end{array}$ \\
\hline Shipping & EE & H & H \\
Material landed & L & EE & A \\
$\begin{array}{l}\text { Legal } \\
\text { compliance }\end{array}$ & L & EE & EE \\
\hline
\end{tabular}

the evaluations made by EG 3 for the level 3 metrics of the transportation level 2 metric.

After all the pairwise comparison matrices are created by the evaluations of expert groups, Pythagorean fuzzy AHP steps are applied and the metrics weights are calculated. However, before this step, it is investigated whether the evaluations of the expert groups are consistent and if the pairwise comparisons are not consistent, the opinions of the expert groups are re-evaluated. If the consistency ratio is calculated as less than 0.1, the relevant matrix is accepted as consistent and the weight calculation step is started. After all pairwise comparison matrices are determined consistently, the weights of criteria and sub-criteria are calculated. Table 7 shows the criteria and sub-criteria weights calculated considering each expert group, by Pythagorean fuzzy AHP.

The level 1 and level 2 metrics weight of 3 different expert groups are aggregated and then the priority scores for each level 3 metrics are calculated as in Table 8 , by multiplying the aggregated level 3 metrics weights with the corresponding level 2 and level 1 weights.

If the level 3 metrics are focused on, partner integration is the most important level 3 metrics with the biggest importance rate of 0.085 among all 58 different level 3 metrics. It can be said that partner integration has more impact on whole supply chain performance evaluation than the other level 3 metrics. Then, material cost for production must be taken into consideration, with an importance level of 0.058 . In addition, the least important level 3 metrics are obtained as supply chain fixed assets, other methods for digital technology's methods, return risk, and accounts payable with importance levels less than 0.004 .

In the case of level 1 metric as a reliability, it appears that damage free orders, fill rate and order fulfilment are absolutely more important than other level 3 metrics. Looking at the flexibility as to the level 1 metric, it appears that there is no
Table 5 Pairwise comparison of EG 2 for system

\begin{tabular}{lllll}
\hline System & System structure & Consistency & Applicability & Transparency \\
\hline System structure & EE & BA & AA & A \\
Consistency & AA & EE & BA & AA \\
Applicability & BA & AA & EE & H \\
Transparency & EE & BA & L & EE \\
\hline
\end{tabular}


Table 7 Weights of the level 2 and level 3

\begin{tabular}{|c|c|c|c|c|c|c|c|c|}
\hline Level 1 metric & Level 2 metric & EG 1 & EG 2 & EG 3 & Level 3 metric & EG 1 & EG 2 & EG 3 \\
\hline \multirow[t]{9}{*}{ Reliability } & \multirow[t]{3}{*}{ Quantity } & \multirow[t]{3}{*}{0.263} & \multirow[t]{3}{*}{0.143} & \multirow[t]{3}{*}{0.263} & Maximum delivery amount & 0.104 & 0.200 & 0.263 \\
\hline & & & & & Maximum delivery time & 0.448 & 0.400 & 0.475 \\
\hline & & & & & Average delivery time & 0.448 & 0.400 & 0.263 \\
\hline & \multirow[t]{3}{*}{ Accuracy } & \multirow[t]{3}{*}{0.475} & \multirow[t]{3}{*}{0.279} & \multirow[t]{3}{*}{0.263} & Delivery performance & 0.278 & 0.279 & 0.263 \\
\hline & & & & & Document accuracy & 0.067 & 0.143 & 0.475 \\
\hline & & & & & Order fulfillment & 0.655 & 0.578 & 0.263 \\
\hline & \multirow[t]{3}{*}{ Quality } & \multirow[t]{3}{*}{0.263} & \multirow[t]{3}{*}{0.578} & \multirow[t]{3}{*}{0.475} & Damage free orders & 0.648 & 0.279 & 0.483 \\
\hline & & & & & Faultless installations & 0.033 & 0.143 & 0.250 \\
\hline & & & & & Fill rate & 0.320 & 0.578 & 0.267 \\
\hline \multirow[t]{9}{*}{ Flexibility } & \multirow[t]{3}{*}{ Production } & \multirow[t]{3}{*}{0.400} & \multirow[t]{3}{*}{0.279} & \multirow[t]{3}{*}{0.400} & Plan flexibility & 0.081 & 0.483 & 0.200 \\
\hline & & & & & Production flexibility & 0.043 & 0.250 & 0.400 \\
\hline & & & & & Supply chain adaptability & 0.876 & 0.267 & 0.400 \\
\hline & \multirow[t]{3}{*}{ Delivery } & \multirow[t]{3}{*}{0.200} & \multirow[t]{3}{*}{0.578} & 0.200 & Response time & 0.289 & 0.204 & 0.289 \\
\hline & & & & & Quantity change in supply & 0.289 & 0.407 & 0.289 \\
\hline & & & & & Lead time change in deliver & 0.422 & 0.390 & 0.422 \\
\hline & Risk & 0.400 & 0.143 & 0.400 & Production & 0.279 & 0.143 & 0.448 \\
\hline & & & & & Return & 0.143 & 0.279 & 0.104 \\
\hline & & & & & Delivery & 0.578 & 0.578 & 0.448 \\
\hline Responsiveness & Cycle time & 0.197 & 0.346 & 0.654 & Delivery retail cycle time & 0.578 & 0.279 & 0.400 \\
\hline & & & & & Source cycle time & 0.143 & 0.143 & 0.200 \\
\hline & & & & & Delivery cycle time & 0.279 & 0.578 & 0.400 \\
\hline & Quantity supplied & 0.803 & 0.654 & 0.346 & Supply by type & 0.663 & 0.279 & 0.278 \\
\hline & & & & & Supply by region & 0.168 & 0.143 & 0.067 \\
\hline & & & & & Lead time & 0.168 & 0.578 & 0.655 \\
\hline Cost & Production & 0.649 & 0.263 & 0.578 & Material & 0.905 & 0.279 & 0.876 \\
\hline & & & & & Planning & 0.033 & 0.578 & 0.081 \\
\hline & & & & & Management & 0.062 & 0.143 & 0.043 \\
\hline & Transportation & 0.333 & 0.475 & 0.279 & Shipping & 0.502 & 0.578 & 0.671 \\
\hline & & & & & Material landed & 0.473 & 0.279 & 0.159 \\
\hline & & & & & Legal compliance & 0.024 & 0.143 & 0.170 \\
\hline & Maintenance & 0.017 & 0.263 & 0.143 & Service cost & 0.046 & 0.578 & 0.448 \\
\hline & & & & & Warranty cost & 0.046 & 0.279 & 0.104 \\
\hline & & & & & Returns cost & 0.907 & 0.143 & 0.448 \\
\hline Assets & Working capital & 0.297 & 0.279 & 0.544 & Accounts payable & 0.043 & 0.148 & 0.143 \\
\hline & & & & & Accounts receivable & 0.081 & 0.329 & 0.279 \\
\hline & & & & & Inventory & 0.876 & 0.522 & 0.578 \\
\hline & Cash to cash cycle & 0.672 & 0.578 & 0.302 & Days payable outstanding & 0.043 & 0.143 & 0.143 \\
\hline & & & & & Inventory days of supply & 0.876 & 0.578 & 0.578 \\
\hline & & & & & Days sales outstanding & 0.081 & 0.279 & 0.279 \\
\hline & Fixed assets & 0.031 & 0.143 & 0.154 & Asset turns & 0.803 & 0.654 & 0.907 \\
\hline & & & & & Supply chain fixed assets & 0.197 & 0.346 & 0.093 \\
\hline Digital technology & Ability & 0.153 & 0.578 & 0.143 & Dynamism & 0.393 & 0.060 & 0.327 \\
\hline & & & & & Capability & 0.040 & 0.247 & 0.327 \\
\hline & & & & & Innovation & 0.169 & 0.118 & 0.173 \\
\hline & & & & & Collaboration & 0.398 & 0.574 & 0.173 \\
\hline & Methods & 0.080 & 0.143 & 0.279 & Digital mapping & 0.798 & 0.263 & 0.578 \\
\hline
\end{tabular}


Table 7 continued

\begin{tabular}{|c|c|c|c|c|c|c|c|c|}
\hline Level 1 metric & Level 2 metric & EG 1 & EG 2 & EG 3 & Level 3 metric & EG 1 & EG 2 & EG 3 \\
\hline & & & & & Machine learning & 0.040 & 0.475 & 0.279 \\
\hline & & & & & Other methods & 0.163 & 0.263 & 0.143 \\
\hline & System & 0.766 & 0.279 & 0.578 & System structure & 0.129 & 0.217 & 0.168 \\
\hline & & & & & Consistency & 0.509 & 0.264 & 0.396 \\
\hline & & & & & Applicability & 0.240 & 0.377 & 0.396 \\
\hline & & & & & Transparency & 0.122 & 0.142 & 0.040 \\
\hline \multirow[t]{6}{*}{ Information systems } & Integration & 0.803 & 0.346 & 0.654 & Integrated database & 0.105 & 0.279 & 0.263 \\
\hline & & & & & Integrated interfaces & 0.026 & 0.578 & 0.263 \\
\hline & & & & & Partner integration & 0.869 & 0.143 & 0.475 \\
\hline & Content & 0.197 & 0.654 & 0.346 & Consistent data & 0.766 & 0.400 & 0.204 \\
\hline & & & & & Comprehensibility & 0.153 & 0.400 & 0.390 \\
\hline & & & & & Comprehensiveness & 0.080 & 0.200 & 0.407 \\
\hline
\end{tabular}

big difference between importance levels of level 3 metrics. For responsiveness level 1 metric, supply by type is the most important level 3 metric and source cycle time is the least important. Production cost and shipping cost are the most important level 3 metrics for level 1 metric of cost. Inventory days of supply and inventory have more importance levels than the sum of other level 3 metrics for assets as a level 1 metric.

If we focus on digital technology as a newly level 1 metric system is almost twice as important as ability and methods. Digital technology has three level 3 metrics that have above average importance among its eleven level 3 metrics. Consistency, applicability, and collaboration have above average importance. Other level 3 metrics have an importance level less than 0.01 .

Information system is the most important level 1 metric. It has two level 2 metrics as integration and content. Integration is the most important level 2 metric among all level 2 metrics for the whole system. Partner integration is more than three times important than integrated database and integrated interfaces for integration case. Content's level 3 metrics consistent data, comprehensibility, and comprehensiveness have $0.38,0.34$, and 0.23 importance levels, respectively.

In this study, the SCOR model is extended with new metrics to construct SCOR 4.0 model in a hierarchical metric structure. With the proposed Best worst-integrated Pythagorean fuzzy AHP methodology, the weights of each performance metric are determined by getting expert opinions. It is shown that the proposed SCOR 4.0 model and decision-making methodology provide good solutions by evaluating its results for a real supply chain application.

\section{Conclusions}

Supply chains have great importance in today's world. In this context, efficient management of supply chains is necessary both economically and in terms of time. Therefore, the performance of supply chains should be evaluated, carefully. The SCOR model is one of the most commonly used supply chain performance measurement methodologies. With the developing technology, it is inevitable to add new performance measurement metrics to the supply chain performance evaluation. For this reason, the SCOR model should be updated with new needs. In this paper performance evaluation of the supply chains in today's world is taken into consideration. The performance evaluation model is structured as a threelevel hierarchical structure to evaluate the supply chains. Then, a novel SCOR 4.0 model is proposed with new metrics. Subsequently, a hybrid Best worst-Pythagorean fuzzy AHP methodology is presented to determine the importance levels of each level of metrics. In the problem, the oil supply chain, which is one of the most used materials for today's world, is handled and a real application is presented.

The contributions of the paper to the literature and application can be specified as follows: (1) by this paper, new metrics are added into the SCOR model to adapt it to the Industry 4.0 world. Thus, a novel SCOR 4.0 model is proposed that will be used by both public and private sectors to improve their supply chain strategies; (2) the most important metrics on the supply chain performances are determined and classified; (3) three different expert groups are created to take opinions about metrics; (4) main Level 1 metrics are evaluated by the Best Worst Method; (5) their sub-factors (inner levels) are evaluated by the Pythagorean fuzzy AHP method and the importance weights of each Level 2 And Level 3 metrics are obtained; and (6) a real application for an oil supply 
Table 8 Aggregated weights of level 3 metrics

\begin{tabular}{|c|c|c|c|}
\hline Level 3 metrics & Weight & Level 3 metrics & Weigh \\
\hline $\begin{array}{l}\text { Maximum delivery } \\
\text { amount }\end{array}$ & 0.009 & Legal compliance & 0.006 \\
\hline $\begin{array}{l}\text { Maximum delivery } \\
\text { time }\end{array}$ & 0.023 & Service cost & 0.011 \\
\hline Average delivery time & 0.019 & Warranty cost & 0.004 \\
\hline Delivery performance & 0.021 & Returns cost & 0.006 \\
\hline Document accuracy & 0.015 & Accounts payable & 0.004 \\
\hline Order fullfilment & 0.041 & Accounts receivable & 0.008 \\
\hline Damage free orders & 0.043 & Inventory & 0.021 \\
\hline Faultless installations & 0.016 & $\begin{array}{r}\text { Days payable } \\
\text { outstanding }\end{array}$ & 0.005 \\
\hline Fill rate & 0.041 & $\begin{array}{l}\text { Inventory days of } \\
\text { supply }\end{array}$ & 0.032 \\
\hline Plan flexibility & 0.007 & Days sales outstanding & 0.009 \\
\hline Production flexibility & 0.007 & Asset turns & 0.008 \\
\hline $\begin{array}{l}\text { Supply chain } \\
\text { Adaptability }\end{array}$ & 0.016 & $\begin{array}{l}\text { Supply chain fixed } \\
\text { assets }\end{array}$ & 0.002 \\
\hline Response time & 0.006 & Dynamism & 0.005 \\
\hline $\begin{array}{l}\text { Quantity change in } \\
\text { supply }\end{array}$ & 0.009 & Capability & 0.007 \\
\hline $\begin{array}{l}\text { Lead time change in } \\
\text { deliver }\end{array}$ & 0.011 & Innovation & 0.004 \\
\hline Production & 0.008 & Collaboration & 0.014 \\
\hline Return & 0.004 & Digital mapping & 0.009 \\
\hline Delivery & 0.013 & Machine learning & 0.005 \\
\hline $\begin{array}{l}\text { Delivery retail cycle } \\
\text { time }\end{array}$ & 0.017 & Other methods & 0.003 \\
\hline Source cycle time & 0.008 & System structure & 0.009 \\
\hline Delivery cycle time & 0.019 & Consistency & 0.024 \\
\hline Supply by type & 0.030 & Applicability & 0.018 \\
\hline Supply by region & 0.009 & Transparency & 0.005 \\
\hline Lead time & 0.027 & Intergrated database & 0.028 \\
\hline Material & 0.059 & Integrated interfaces & 0.032 \\
\hline Planning & 0.011 & Partner integration & 0.085 \\
\hline Management & 0.005 & Consistent data & 0.039 \\
\hline Shipping & 0.032 & Comprehensibility & 0.034 \\
\hline Material landed & 0.017 & Comprehensivenes & 0.023 \\
\hline
\end{tabular}

chain is presented to show the applicability and reliability of the methodology.

Broadly stated, some future directions can be considered into the following parts: different aggregation operators and operation rules on Pythagorean fuzzy sets can be applied. Different calculus for the Pythagorean fuzzy sets can be presented. Some new multi-criteria decision-making methods can be included to ensure a more comparative and integrated study as a future direction. Except the methods used in the paper, some of the most representative computational intelligence algorithms can be used to solve the perfor- mance evaluation problem, such as genetic algorithm (GA), monarch butterfly optimization (MBO), earthworm optimization algorithm (EWA), elephant herding optimization (EHO), and moth search (MS) algorithm. The organizations can be compared using this work or it can be expanded by discussing with more experts.

Open Access This article is licensed under a Creative Commons Attribution 4.0 International License, which permits use, sharing, adaptation, distribution and reproduction in any medium or format, as long as you give appropriate credit to the original author(s) and the source, provide a link to the Creative Commons licence, and indicate if changes were made. The images or other third party material in this article are included in the article's Creative Commons licence, unless indicated otherwise in a credit line to the material. If material is not included in the article's Creative Commons licence and your intended use is not permitted by statutory regulation or exceeds the permitted use, you will need to obtain permission directly from the copyright holder. To view a copy of this licence, visit http://creativecomm ons.org/licenses/by/4.0/.

\section{References}

1. Balcik B, Beamon BM (2008) Facility location in humanitarian relief. Int J Logist Res Appl 11(2):101-121. https://doi.org/10.108 0/13675560701561789

2. Ozyazar O, Yardimci I, Vayvay O (2014) Lojistik ve Tedarik Zinciri Performans Ölçümü: Literatür Taramasi

3. Lebas MJ (1995) Performance measurement and performance management. Int J Prod Econ 41(1-3):23-35. https://doi.org/10. 1016/0925-5273(95)00081-X

4. Wouters M (2009) A developmental approach to performance measures-results from a longitudinal case study. Eur Manag $\mathbf{J}$ 27(1):64-78. https://doi.org/10.1016/j.emj.2008.06.006

5. Gunasekaran A, Patel C, McGaughey RE (2004) A framework for supply chain performance measurement. Int $\mathrm{J}$ Prod Econ 87(3):333-347. https://doi.org/10.1016/j.ijpe.2003.08.003

6. Wang G, Huang SH, Dismukes JP (2004) Product-driven supply chain selection using integrated multi-criteria decision-making methodology. Int J Prod Econ 91(1):1-15. https://doi.org/10.1016/ S0925-5273(03)00221-4

7. Wang G, Huang SH, Dismukes JP (2005) Manufacturing supply chain design and evaluation. Int $\mathbf{J}$ Adv Manuf Technol 25(1-2):93-100. https://doi.org/10.1007/s00170-003-1791-y

8. Hwang YD, Lin YC, Lyu J (2008) The performance evaluation of SCOR sourcing process - the case study of Taiwan's TFT-LCD industry. Int J Prod Econ 115(2):411-423. https://doi.org/10.1016/ j.ijpe.2007.09.014

9. Chae B (2009) Developing key performance indicators for supply chain: an industry perspective. Supply Chain Manag 14(6):422-428. https://doi.org/10.1108/13598540910995192

10. Raut RD, Bhasin HV, Kamble SS (2012) Supplier selection using integrated multi-criteria decision-making methodology. Int J Oper Res 13(4):359-394. https://doi.org/10.1504/IJOR.2012.046223

11. Lu Q, Goh M, De Souza R (2016) A SCOR framework to measure logistics performance of humanitarian organizations. J Humanit Logist Supply Chain Manag 6(2):222-239. https://doi.org/10.110 8/JHLSCM-09-2015-0038

12. Essakly A, Wichmann M, Spengler TS (2019) A reference framework for the holistic evaluation of Industry 4.0 solutions for small-and medium-sized enterprises. IFAC PapersOnLine 52(13):427-432. https://doi.org/10.1016/j.ifacol.2019.11.093

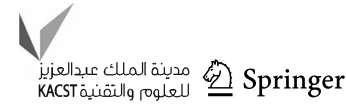


13. Lima-Junior FR, Carpinetti LCR (2020) An adaptive networkbased fuzzy inference system to supply chain performance evaluation based on SCOR ${ }^{\circledR}$ metrics. Comput Ind Eng 139:106191. https://doi.org/10.1016/j.cie.2019.106191

14. Lockamy A, Mccormack K (2004) The development of a supply chain management process maturity model using the concepts of business process orientation. Supply Chain Manag An Int J 9(4):272-278. https://doi.org/10.1108/13598540410550019

15. Ntabe EN, LeBel L, Munson AD, Santa-Eulalia LA (2015) A systematic literature review of the supply chain operations reference (SCOR) model application with special attention to environmental issues. Int J Prod Econ 169:310-332. https://doi.org/10.1016/j. ijpe.2015.08.008

16. Müller JM (2019) Contributions of Industry 4.0 to quality management-a SCOR perspective. IFAC-PapersOnLine 52(13):1236-1241. https://doi.org/10.1016/j.ifacol.2019.11.367

17. Kocaoğlu B, Gülsün B, Tanyaş M (2013) A SCOR based approach for measuring a benchmarkable supply chain performance. J Intell Manuf 24(1):113-132. https://doi.org/10.1007/s10845-011-0547Z

18. Bushuev MA, Guiffrida AL (2019) Improving delivery performance for gamma distributed delivery time. Int $\mathrm{J}$ Bus Perform Supply Chain Model 10(3):195-214. https://doi.org/10.150 4/IJBPSCM.2019.100823

19. Sambasivan M, Mohamed ZA, Nandan T (2009) Performance measures and metrics for e-supply chains. J Enterp Inf Manag 22(3):346-360. https://doi.org/10.1108/17410390910949751

20. Lin FR, Shaw MJ (1998) Reengineering the order fulfillment process in supply chain networks. Int J Flex Manuf Syst 10(3):197-229. https://doi.org/10.1023/A:1008069816606

21. Sanayei A, Farid Mousavi S, Abdi MR, Mohaghar A (2008) An integrated group decision-making process for supplier selection and order allocation using multi-attribute utility theory and linear programming. J Franklin Inst 345(7):731-747. https://doi.org/10. 1016/j.jfranklin.2008.03.005

22. Zahara F, Hadiguna RA (2017) SCOR based key success factors in cooking oil supply chain buyers perspective in Padang City. AIP Conf Proc 1902(1):020055. https://doi.org/10.1063/1.5010672

23. Vanichchinchai A, Igel B (2011) The impact of total quality management on supply chain management and firm's supply performance. Int J Prod Res 49(11):3405-3424. https://doi.org/10.10 80/00207543.2010.492805

24. Eckstein D, Goellner M, Blome C, Henke M (2015) The performance impact of supply chain agility and supply chain adaptability: the moderating effect of product complexity. Int $\mathrm{J}$ Prod Res 53(10):3028-3046. https://doi.org/10.1080/00207543.2014.97070 7

25. Schütz P, Tomasgard A (2011) The impact of flexibility on operational supply chain planning. Int J Prod Econ 134(2):300-311. https://doi.org/10.1016/j.ijpe.2009.11.004

26. Liu X, Ma S (2006) How to measure the logistics capability in supply chain: calculation model of circulation quantity and response time. Accessed 26 Apr 2020. [Online]. https://www. logistics-chain.com

27. Lin Y, Zhou L (2011) The impacts of product design changes on supply chain risk: a case study. Int J Phys Distrib Logist Manag 41(2):162-186. https://doi.org/10.1108/09600031111118549

28. Seuring SA (2002) Green supply chain costing: joint cost management in the polyester linings supply chain. Greener Manag Int 33: 71-80. https://www.jstor.org/stable/greemanainte.33.71

29. Ceran Y, Alagöz A (2007) Lojistik Maliyet Yönetimi: Lojistik Maliyetler Ve Lojistik Maliyet Muhasebesi

30. Shao XF (2017) Free or calculated shipping: impact of delivery cost on supply chains moving to online retailing. Int J Prod Econ 191:267-277. https://doi.org/10.1016/j.ijpe.2017.06.022
31. Lima-Junior FR, Carpinetti LCR (2016) Combining SCOR ${ }^{\circledR}$ model and fuzzy TOPSIS for supplier evaluation and management. Int $\mathrm{J}$ Prod Econ 174:128-141. https://doi.org/10.1016/j.ijpe.2016.01.02 3

32. Zhou YW, Guo J, Zhou W (2018) Pricing/service strategies for a dual-channel supply chain with free riding and service-cost sharing. Int J Prod Econ 196:198-210. https://doi.org/10.1016/j.ijpe.2017. 11.014

33. Goldparvar M, Seifbarghy M (2009) Application of scor model in an oil-producing company. J Optim Ind Eng 4(4): 59-69. https:// www.sid.ir/en/journal/ViewPaper.aspx $? i d=218737$

34. Hofmann E, Kotzab H (2010) A supply chain-oriented approach of working capital management. J Bus Logist 31(2):305-330. https:// doi.org/10.1002/j.2158-1592.2010.tb00154.x

35. Gelsomino LM, Mangiaracina R, Perego A, Tumino A (2016) Supply chain finance: a literature review. Int J Phys Distrib Logist Manag 46(4):348-366. https://doi.org/10.1108/IJPDLM-08-20140173

36. Topaloğlu EE, Karakozak Ö, Ege İ (2016) Nakit Dönüşüm Süresi Analizi: Bıst-50 Endeksinde Yer Alan Şirketler Üzerine Ampirik Bir Uygulama. Niğde Üniversitesi İktisadi ve İdari Bilim. Fakültesi Derg 9(1): 179-193. [Online]. https://dergipark.ulakbim.gov. tr/niguiibfd/. Accessed 27 Apr 2020

37. Moyer RC, McGuigan JR, Rao RP (2006) Fundamentals of contemporary financial management. Thomson/South-Western, Mason

38. Liebl J, Hartmann E, Feisel E (2016) Reverse factoring in the supply chain: objectives, antecedents and implementation barriers. Int $\mathrm{J}$ Phys Distrib Logist Manag 46(4):393-413. https://doi.org/10.110 8/IJPDLM-08-2014-0171

39. Altay N, Ramirez A (2010) Impact of disasters on firms in different sectors: implications for supply chains. J Supply Chain Manag 46(4):59-80. https://doi.org/10.1111/j.1745-493X.2010.03206.x

40. Gölzer P, Cato P, Amberg M (2015) Association for information systems data processing requirements of industry 4.0-use cases for big data applications recommended citation

41. Winter SG (2003) Understanding dynamic capabilities. Strateg Manag J Strat Manag J 24:991-995. https://doi.org/10.1002/smj.3 18

42. Teece DJ (2014) The foundations of enterprise performance: dynamic and ordinary capabilities in an (economic) theory of firms. Acad Manag Perspect 28(4):328-352. https://doi.org/10.5 465/amp.2013.0116

43. Asdecker B, Felch V (2018) Development of an Industry 4.0 maturity model for the delivery process in supply chains. J Model Manag 13(4):840-883. https://doi.org/10.1108/JM2-03-2018-0042

44. Gilchrist A (2016) Middleware industrial internet of thingsplatforms. Industry 4.0: the industrial internet of the things. Springer, Berlin, pp 153-160

45. Sharma R, Kamble SS, Gunasekaran A, Kumar V, Kumar A (2020) A systematic literature review on machine learning applications for sustainable agriculture supply chain performance. Comput Oper Res 119:104926. https://doi.org/10.1016/j.cor.2020.104926

46. Varghese A, Tandur D (2014) Wireless requirements and challenges in Industry 4.0. In 2014 International Conference on Contemporary Computing and Informatics (IC3I) (pp.634-638). https://doi.org/1 0.1109/IC3I.2014.7019732

47. Kagermann $\mathrm{H}$ (2015) Change through digitization value creation in the age of industry 4.0. Managementof permanent change. Springer, Berlin, pp 23-45

48. Papadonikolaki E (2020) The digital supply chain: mobilising supply chain management philosophy toreconceptualise digital technologies and building information modelling (BIM). In: Pryke S (ed) Successful Construction Supply Chain Management: Conceptsand Case Studies, 2nd edn. Wiley, London 
49. Kurpjuweit S, Schmidt CG, Klöckner M, Wagner SM (2019) Blockchain in additive manufacturing and its impact on supply chains. J Bus Logist. https://doi.org/10.1111/jbl.12231

50. Lamming RC, Caldwell ND, Harrison DA, Phillips W (2001) Transparency in supply relationships: concept and practice. J Supply Chain Manag 37(3):4-10. https://doi.org/10.1111/j.1745-493 X.2001.tb00107.x

51. Zhou Keliang, Taigang Liu, Lifeng Zhou (2015) Industry 4.0: Towards Future Industrial Opportunities and Challenges. In: FSKD'15. 12th International Conference on Fuzzy Systems and Knowledge Discovery, Zhangiajie, China, 15 - 17 August 2015. New York: IEEE, pp 2147-2152. https://doi.org/10.1109/FSKD.2 015.7382284

52. Biahmou A, Emmer C, Stjepandic J (2016) Digital master as an enabler for industry 4.0 3D measurement data management view project. https://doi.org/10.3233/978-1-61499-703-0-672

53. Ilbahar E, Cebi S, Kahraman C (2019) A state-of-the-art review on multi-attribute renewable energy decision making. Energy Strategy Rev 25:18-33. https://doi.org/10.1016/j.esr.2019.04.014

54. Liao H, Mi X, Yu Q, Luo L (2019) Hospital performance evaluation by a hesitant fuzzy linguistic best worst method with inconsistency repairing. J Clean Prod 232:657-671. https://doi.org/10.101 6/j.jclepro.2019.05.308

55. Rezaei J (2015) Best-worst multi-criteria decision-making method. Omega (United Kingdom) 53:49-57. https://doi.org/10.1016/j. omega.2014.11.009

56. Mou Q, Xu Z, Liao H (2016) An intuitionistic fuzzy multiplicative best-worst method for multi-criteria group decision making. Inf Sci (Ny) 374:224-239. https://doi.org/10.1016/j.ins.2016.08.074

57. Kheybari S, Kazemi M, Rezaei J (2019) Bioethanol facility location selection using best-worst method. Appl Energy 242:612-623. https://doi.org/10.1016/j.apenergy.2019.03.054

58. Zadeh LA (1965) Fuzzy sets. Inf Control 8(3):338-353. https://doi. org/10.1016/S0019-9958(65)90241-X

59. Ayyildiz E, Taskin Gumus A (2020) A novel spherical fuzzy AHP-integrated spherical WASPAS methodology for petrol station location selection problem: a real case study for İstanbul. Environ Sci Pollut Res. https://doi.org/10.1007/s11356-020-09640-0

60. Wang JQ, Peng JJ, Zhang HY, Liu T, Chen XH (2015) An uncertain linguistic multi-criteria group decision-making method based on a cloud model. Gr Decis Negot 24(1):171-192. https://doi.org/10.1 007/s10726-014-9385-7

61. Guyonnet D, Touze-Foltz N (2014) Assessing the risk of leakage from heap leach pads used in mining operations. Extr Ind Soc 1(1):96-103. https://doi.org/10.1016/j.exis.2013.12.002

62. Yager RR (2013) Pythagorean fuzzy subsets. In: IFSA worldcongress and NAFIPS annual meeting (IFSA/NAFIPS), 2013 joint, IEEE. https://doi.org/10.1109/ifsa-nafips.2013.6608375

63. Wang L, Li N (2020) Pythagorean fuzzy interaction power Bonferroni mean aggregation operators in multiple attribute decision making. Int J Intell Syst 35(1):150-183. https://doi.org/10.1002/ int. 22204

64. Li N, Garg H, Wang L (2019) Some novel interactive hybridweighted aggregation operators with pythagorean fuzzy numbers and their applications to decision making. Mathematics 7(12):1150. https://doi.org/10.3390/MATH7121150

65. Wang L, Li N (2019) Continuous interval-valued Pythagorean fuzzy aggregation operators for multiple attribute group decision making. J Intell Fuzzy Syst 36(6):6245-6263. https://doi.org/10.3 233/JIFS-182570
66. Yucesan M, Gul M (2020) Hospital service quality evaluation: an integrated model based on Pythagorean fuzzy AHP and fuzzy TOPSIS. Soft Comput 24(5):3237-3255. https://doi.org/10.1007/s005 00-019-04084-2

67. Gul M, Ak MF, Guneri AF (2019) Pythagorean fuzzy VIKORbased approach for safety risk assessment in mine industry. J Saf Res 69:135-153. https://doi.org/10.1016/j.jsr.2019.03.005

68. Özkan B, Kaya İ, Erdoğan M, Karaşan A (2020) Evaluating blockchain risks by using a MCDM methodology based on pythagorean fuzzy setsv vol 1029. Springer International Publishing, Berlin

69. Karasan A, Kaya İ, Erdoğan M, Budak A (2020) Risk analysis of the autonomous vehicle driving systems by using pythagorean fuzzy AHP. Adv Intell Syst Comput 1029:926-934. https://doi.org/ 10.1007/978-3-030-23756-1_110

70. Yildiz A, Ayyildiz E, Gumus AT, Ozkan C (2020) A modified balanced scorecard based hybrid Pythagorean Fuzzy AHP-topsis methodology for ATM site selection problem. Int J Inf Technol Decis Mak 19(02):365-384. https://doi.org/10.1142/S021962202 0500017

71. Peng X, Selvachandran G (2019) Pythagorean fuzzy set: state of the art and future directions. Artif Intell Rev 52(3):1873-1927. https:// doi.org/10.1007/s10462-017-9596-9

72. Atanassov K (1999) Intuitionistic fuzzy sets: theory and applications. Physica-Verlag, Heidelberg

73. Yager RR (2014) Pythagorean membership grades in multicriteria decision making. IEEE Trans Fuzzy Syst 22(4):958-965. https:// doi.org/10.1109/TFUZZ.2013.2278989

74. Ilbahar E, Karaşan A, Cebi S, Kahraman C (2018) A novel approach to risk assessment for occupational health and safety using Pythagorean fuzzy AHP \& fuzzy inference system. Saf Sci 103:124-136. https://doi.org/10.1016/j.ssci.2017.10.025

75. Karasan A, Ilbahar E, Cebi S, Kahraman C (2018) A new risk assessment approach: safety and critical effect analysis (SCEA) and its extension with Pythagorean fuzzy sets. Saf Sci 108:173-187. https://doi.org/10.1016/j.ssci.2018.04.031

76. Ak MF, Gul M (2019) AHP-TOPSIS integration extended with Pythagorean fuzzy sets for information security risk analysis. Complex Intell Syst 5:113-126. https://doi.org/10.1007/s40747-018-0 087-7

77. Kumar R, Edalatpanah SA, Jha S, Singh R (2019) A Pythagorean fuzzy approach to the transportation problem. Complex Intell Syst 5(2):255-263. https://doi.org/10.1007/s40747-019-0108-1

78. Garg H (2017) A new improved score function of an intervalvalued pythagorean fuzzy set based topsis method. Int $\mathbf{J}$ Uncertain Quantif 7(5):463-474. https://doi.org/10.1615/Int.J. UncertaintyQuantification.2017020197

79. Garg H (2016) A novel accuracy function under interval-valued Pythagorean fuzzy environment for solving multicriteria decision making problem J. Intell Fuzzy Syst 31(1):529-540. https://doi. org/10.3233/IFS-162165

80. Peng X, Yang Y (2016) Fundamental properties of intervalvalued Pythagorean fuzzy aggregation operators. Int J Intell Syst 31(5):444-487. https://doi.org/10.1002/int.21790

81. Ayyildiz E, Taskin Gumus A, Erkan M (2020) Individual credit ranking by an integrated interval type-2 trapezoidal fuzzy Electre methodology. Soft Comput. https://doi.org/10.1007/s00500-020-0 4929-1 
82. Yılmaz N et al (2017) İş sağlığı ve güvenliği risk değerlendirme süreci için bulanık çok kriterli bir model ve uygulaması. J Fac Eng Archit Gazi Univ 32:77-87. https://doi.org/10.17341/gazimmfd.3 00597

83. Saaty TL (1977) A scaling method for priorities in hierarchical structures. J Math Psychol 15(3):234-281. https://doi.org/10.101 6/0022-2496(77)90033-5

84. Wu XF, Chen GQ (2019) Global overview of crude oil use: From source to sink through inter-regional trade. Energy Policy 128:476-486. https://doi.org/10.1016/j.enpol.2019.01.022
85. Neuman M, Tissot RR, Mabrey D (2019) Are Ugandan's firms ready to take advantage of the country's new opportunities in the oil industry? Extr Ind Soc 6(2):293-312. https://doi.org/10.1016/j. exis.2018.10.007

Publisher's Note Springer Nature remains neutral with regard to jurisdictional claims in published maps and institutional affiliations. 